\title{
PERCEBER, MOVER, CRIAR - PROCESSOS DE TRANSFORMAÇÃO
}

\author{
PERCEPTION, MOVEMENT, CREATION - TRANSFORMATION PROCESSES \\ PERCIBIR, MOVER, CREAR - PROCESOS DE TRANSFORMACIÓN
}

Katharina Doring*

katharina.doring@gmail.com

\begin{abstract}
REVISTA PEDAGÓGICA
Revista do Programa de Pós-graduação em Educação da Unochapecó | ISSN 1984-1566

Universidade Comunitária da Região de Chapecó | Chapecó-SC, Brasil

Como referenciar este artigo: DORING, K. Perceber, mover, criar - processos de transformação. Revista Pedagógica, Chapecó, v. 17, n. 35, p. 136-162, maio/ago. 2015.
\end{abstract}

\begin{abstract}
RESUMO: O presente artigo traz uma reflexão sobre a importância dos processos da percepção multissensorial e a sua relaçấo com expressões estéticas, criativas e transformadoras em e com os sentidos, mediante um ciclo-triangulo que se autoalimenta continuamente, gerando uma espiral criativa entre Perceber - Mover Criar. Trabalho com autores-pesquisadores de diversas áreas (música, filosofia, artes e educação, neurobiologia etc.), trazendo teorias e reflexões de ângulos diferentes, tecendo redes e pensamentos sistêmicas sobre processos de percepção, criação e transformação que começam com cada indivíduo, no seu "sistema integrado" e subjetivo de corpo-mente-alma. Utilizo o conceito da autopoiese como um das basilares para a reconstrução e compreensão diferenciada da importância das artes e da arte-educação, superando dicotomias obsoletas entre emoção e razão, imaterial e material, supérfluo e utilitário, entre outros do sistema educacional brasileiro mecanicista e monótono, que parece ter absorvido pouco dos avanços inter/nacionais na área das artes, da pedagogia contemporânea e das neurociências que comprovem a necessidade do pensamento complexo e criativo.
\end{abstract}

PALAVRAS-CHAVE: Percepção multissensorial. Autopoiese. Transformação.

ABSTRACT: The present article comes along with a reflection on the importance of multisensory perception and its relation with aesthetic, creative and transformative expressions in and with all senses, by the use of a cycle/ triangle, which feeds on itself continuously, generating a creative spiral between perceiving, moving, creating. I work with researchers/authors, from various fields (music, philosophy, arts education, neurobiology, etc.), bringing theories and reflections from different angles, weaving nets and contemplations systemically about processes of perception, creation and transformation, which take its beginning in every single person, in its integrated and subjective 'system' of body-mind-soul. I work with the idea of autopoiese being one of the basics for the differentiated comprehension and reconstruction of the importance of arts and arts education, overcoming obsolete dichotomies between emotion - rationality, immaterial - material, superfluous - utilitarian, among others, which dominates the current Brazilian educational system, being mechanistic and monotonous. It appears that it has very little absorbed from inter/ national advances in the field of arts, contemporaneous pedagogy and neurosciences that prove the necessity of creative and complex thinking.

KEYWORDS: Multisensory perception. Autopoiesis. Transformation.

RESUMEN: Este artículo presenta una reflexión sobre la importancia de los procesos de la percepción multi-sensorial además su relación con las expresiones estéticas, creativas y transformadoras en e con todos los sentidos, a través de un ciclo-triangulo que se alimenta de sí mismo de forma continua, generando una espiral creativa entre percepción, movimiento, creación. Trabajo con autores e investigadores de varias áreas (música, filosofía, artes y educación, neurobiología, etc.), trayendo teorías y reflexiones desde diferentes ángulos, tejiendo redes y pensamientos sistémicos acerca de los procesos de percepción, creación y transformación, comenzando con cada individuo, en su 'sistema integrado' e subjetivo de cuerpo-mente-alma. Yo uso el concepto de autopoiese como un dos basilares para la reconstrucción e comprensión diferenciada de la importancia de las artes e de la artes-educación, superando dicotomías obsoletas entre emoción y razón, inmaterial y material, superfluo y utilitario, entre otros de lo sistema educacional brasileño presente, mecanicista e monótono, que parece haber absorbido poco de los avances inter/nacionales en la área de las artes, de la pedagogía contemporánea e de las neurociencias que demuestren la necesidad de lo pensamiento complexo e creativo.

PALAVRAS CLAVE: Percepción multisensorial. Autopoiesis. Transformación. 
* Doutora em Educação (2011) com ênfase em Arte-Educação pela Universidade Siegen - programa INEDD/Alemanha. Professora Assistente da UNEB - Departamento de Educação - Área de artes.

1 "Percepção e expressão em tradições cênico musicais afro-brasileiras - aprendizado estético e sensorial no samba de roda do Recôncavo" - no original: Wahrnehmung und Ausdruck in afrobrasilianischen Tanz-Musik-Traditionen sinnlich-ästhetisches Lernen im Samba de Roda - Recôncavo. Dissertation, Uni Siegen, 2011.

\section{INTRODUÇÃO}

Proponho uma reflexão sobre a importância e os processos da percepção multissensorial e sua relação com a expressão criativa e transformadora em e com todos os sentidos, mediante um ciclo-triangulo que se autoalimenta e amplia continuamente, criando uma espiral criativa entre Perceber - Mover - Criar. Trabalhei durante meu doutorado ${ }^{1}$ com alguns autores-pesquisadores de diversas áreas (música, filosofia, artes e educação, neurobiologia), trazendo experiências e reflexões de ângulos diferentes, tecendo redes e pensamentos sistêmicos sobre processos de percepção, criação e transformação que começam com cada indivíduo, no seu "sistema" integrado e subjetivo de corpo-mente-alma. Quero ressaltar que minha pesquisa se situa no campo cultural das culturas populares brasileiras de matriz africana e que os resultados dessa pesquisa tomam explicitamente como referência a diversidade cultural e estética brasileira, e neste artigo não posso aprofundar o contexto cultural específico e me concentro na compreensão das ideias e dos princípios da percepção e expressão estética a partir dos sentidos e da presença corporal para poder reformular as bases da arte-educação no Brasil a partir da memória, presença e ação cultural e estética dos seus povos.

\section{PERCEBER - ENCONTRAR A PRÓPRIA VOZ}

Quando o ser humano escuta a si mesmo, sente sua existência a partir de dentro, de suas sensações e percepções, começa a se dar conta de que todo cotidiano continuamente é determinado por processos de percepção sensorial: ver, ouvir, cheirar, saborear, sentir/tocar, até mesmo intuir/pressentir! No entanto, a maioria desses processos - as sensações/percepções e suas associações psicoemocionais e cognitivas - acontece de forma inconsciente, sendo geralmente impossível para o indivíduo lembrar e reconstituir conscientemente a relação entre sensação, percepção, sentimento, pensamento e (re-)ação. Na contemporaneidade midiática e cibernética, parece cada vez mais que o ser humano emite e reage a impulsos de forma automatizada, utilizando seus sentidos e suas capacidades multissensoriais de forma funcional, mecânica e racionalizada, levando ao atrofiamento do enorme potencial sensorial, poético, flexível, intuitivo, criativo, humano e sentido, na acepção dupla da palavra do sentido sensorial e semântico. A percepção subjetiva muitas vezes é ignorada e subestimada, em prol de uma visão do mundo supostamente objetiva, racional, universal e mecanicista, a qual diminui o crescimento e a aguçamento da autoconsciência do indivíduo e muitas vezes o impede a desenvolver suas próprias formas e maneiras de sentir, perceber e se conscientizar, as quais proporcionam o autoconhecimento e a autoconfiança, que 
${ }^{2} \mathrm{O}$ verbo Können em alemão tem as duas funções semânticas do saber fazer e do poder fazer. por sua vez representam a condição elementar para processos de criação e, mais além, de transformação.

O ser humano necessita permanentemente da afirmação de pertencimento e aceitação social de forma fisiológica e psicoemocional, que experimenta desde recém-nascido mediante a mãe, seu cheiro, seu visual, sua voz, seu tato e seu sabor! Aos poucos, a percepção da criança se amplia e cada vez mais impressões do ambiente sociocultural e natural são incluídas na sua construção subjetiva. Pesquisas neurobiológicas sobre o desenvolvimento pré e pós-natal da criança exemplificam a relação estreita entre o desenvolvimento do bebê e suas percepções e respostas aos impulsos e impactos do seu ambiente, como um diálogo continuo, que somente pode existir e se desenvolver nesse jogo de alternância, na espiral de estímulos, respostas e novas soluções e criações. Essa relação complementar entre a percepção humana e imaterial, multissensorial e multidimensional e as ofertas, os impulsos materiais, sensoriais, intelectuais dos ambientes socioculturais e naturais pode ser reencontrada no debate sobre o aprender e a capacidade de aprender, porque:

Todos os sentidos fazem parte do processo de aprendizagem. Uma boa parte do ato de aprender acontece de forma inconsciente. Aprender leva ao Saber/Poder fazer ${ }^{2}$. A parte inconsciente fornece segurança ao nosso Saber/Fazer. A conexão da nossa atenção para o inconsciente possibilita espontaneidade e controle, e essa relação é experimentado como Fluir ("flow"). (JACOBY, 2000, p. 16).

A noção do flow foi observada e pesquisada pelo psicólogo e professor renomado húngaro-americano Csikszentmihalyi (1960-1996), que o descreveu como um estado de envolvimento profundo numa atividade, por ela mesma, como acontece no brincar da criança, que se encontra esquecida dela mesma. O Ego desaparece, o tempo voa e a pessoa experimenta um prazer imensurável, imersa no fazer, no criar, no brincar, no interagir. Jacoby (2000) compara essa ação à música do jazz, à ação de improvisar musicalmente, ou seja, uma pessoa plenamente absorvida pelo fazer musical, usando as suas habilidades e possibilidades, ou até mesmo se superando. A concentração fluente se observa entre bebês e crianças pequenas quando estão brincando, mesmo que por minutos absorvidos no momento lúdico que pode ser consigo mesmo (corpo, som, movimento) com um objeto ou com outra pessoa interagindo. As crianças pequenas constantemente dialogam com seu meio e as pessoas ao seu redor com seu corpo-mente-alma, buscando o aprendizado de forma integrada, tomando a iniciativa:

Todo mundo é responsável para suas percepções e seu comportamento. Todo mundo somente pode aprender a partir de si mesmo. 
Nos não podemos ensinar a um outro sistema nervosa, percepção e comportamento. No fundo, não podemos ensinar nada a uma outra pessoa. Todo mundo somente aprende para si mesmo com a própria atenção e o próprio comportamento. Ensinar neste sentido, só pode significar que nos conduzimos o aprendiz a situações, que o ajudam a aprender aquilo que ele quer aprender mediante sua própria percepção e ação. Este caminho leva a autonomia. (JACOBY, 2000, p. 28).

A conquista da autonomia requer uma percepção ativa, e não passiva, tendo como base as percepções multissensoriais, ou seja, uma percepção construtiva e interativa que tem a ação e o aprendizado como resultado, uma visão que tem sido estudada de forma interdisciplinar nas neurociências, física quântica, teorias sistêmicas, arte-educação, psicologia da criatividade e trans-pessoal, contribuindo, entre outros, com o surgimento do construtivismo na pedagogia.

Peter Jacoby, professor e cantor lírico alemão, pesquisou a ruptura e transformação de paradigmas científicos, aplicadas ao trabalho vocal, e desenvolveu um modelo de ensino-aprendizagem que utiliza o conceito aprendizado orgânico, para distinguir do aprendizado escolar positivista que reforça prioritariamente processos mentais de forma isolada, sem levar em conta o paradigma da complexidade como resultado de experiências pessoais de vida.

Nós pensamos geralmente que (o aprender) seria o armazenamento de conteúdos intelectuais na memória. Isto certamente é uma forma importante de estudar, mas somente uma forma de aprender. Esse aprender de quantidades, materiais, esta na frente dos nossos hábitos de pensar. Nos aprendemos assim na escola, porque a escola com seus currículos ainda prioriza o saber como uma quantidade de conteúdos e materiais a serem decorados. (JACOBY, 2000, p. 14).

Jacoby (2000) aponta para a necessidade de reestabelecer a relação entre desejo, motivação, estudo, autonomia e "chamado interior", que passa por sensações, percepções e emoções subjetivas. Os fenômenos da percepção, que ocorrem nos níveis psicofísicos e neuroquímicos, não acontecem de forma mecânica, mas sob a influência de inúmeros fatores e acontecimentos internos e externos. O ser humano é um organismo em fluxo contínuo, pois "Nós nos abrimos e fechamos de forma seletiva frente ao ambiente nas demais funções, começando pela atenção e percepção" (Ibid., p. 19), o que confirma o princípio da autopoiese ${ }^{3}$, aqui no campo do aprendizado estético, como um movimento que o sujeito empreende em direção a um som, objeto, uma pessoa ou cena que atrai e desperta o desejo (e/ ou necessidade!) de interagir.
3 Autopoiese (do grego auto "próprio", poiesis "criação"), termo criado nos anos 1970 pelos neurobiólogos chilenos Francisco Varela e Humberto Maturana para designar a capacidade dos seres vivos de produzirem a si próprios. 
Para Maturana, o termo "autopoiese" traduz o que ele chamou de "centro da dinâmica constitutiva dos seres vivos". Para exercê-la de modo autônomo, eles precisam recorrer a recursos do meio ambiente. Em outros termos, são ao mesmo tempo autônomos e dependentes. Trata-se, pois, de um paradoxo. Essa condição paradoxal não pode ser adequadamente entendida pelo pensamento linear, para o qual tudo se reduz à binariedade do sim/não, do ou/ou. Diante de seres vivos, coisas ou eventos, o raciocínio linear analisa as partes separadas, sem empenhar-se na busca das relações dinâmicas entre elas. O paradoxo autonomia-dependência dos sistemas vivos é mais bem compreendido por um sistema de pensamento que englobe o raciocínio sistêmico (que examina as relações dinâmicas entre as partes) e o linear. Eis o pensamento complexo, modelo proposto por Edgar Morin. (MARIOTTI, 1999, p. 1).

O trabalho com um meio invisível e efêmero, a música e o canto, levou Jacoby a buscar novos caminhos, que não criem divisões hierárquicas e mecanicistas, mas que contribuam de forma participativa, colaborativa e equilibrada para todos os processos do organismo ou sistema corpo-mente-alma. $\mathrm{O}$ ato de cantar simboliza bem as fronteiras maleáveis entre pensar e sentir, intenção e intuição, dentro e fora, material e imaterial, entre outros, que fogem da visão newtoniana que invadiu a compreensão do humano, do imaterial e do criativo:

Toda ciência natural foi referida à física [...], toda vida foi banida das ciências; na psicologia, a última visão reducionista foi o Behaviorismo, somente o comportamento medível foi levado em conta. [...] Crianças tinham que ser educadas mediante medidas disciplinatórias, suas vontades tinham que ser quebradas. As consequências de uma educação desumana e sombria, tiveram que ser trabalhadas no nosso século. A isso pertence a imaginação, de que existiria uma técnica perfeita de canto e fala, desconexo das funções vitais da nossa voz. Cantores com essa visão não transmitem sentimentos vivos e sim apenas sons alisados e vazios. (JACOBY, 2000, p. 76).

Um modelo de educação que moldou os ideais e as obras intelectuais e artísticas na Europa e que espalhou uma cópia malfeita nos países em ascensão econômica não faz justiça à dinâmica da vida, da diversidade cultural, criativa e humana, pois tenta forçar a essência da vida em constante transformação, em trilhas estreitas e padrões preestabelecidos.

Hoje por exemplo, entra-se numa escola urbana da China, da Índia ou do Brasil e 
reconhece-se de imediato uma maneira de se organizar a educação que se tornou senso comum no Ocidente. Os alunos se sentam passivamente em salas separadas. Tudo obedece a um plano predeterminado, com sinos, campainhas e regras para manter as coisas funcionando, como uma gigantesca linha de montagem, ao longo das horas, dias e anos. $\mathrm{E}$, realmente, foi a linha de montagem que inspirou a organização da escola da era industrial, cujo fito é obter um produto uniforme e padronizado com a máxima eficiência possível. Embora a necessidade de formar cidadãos globais inteligentes, competentes e solidários divirja em muito, no século XXI, da necessidade de treinar operários no século XIX, a escola da era industrial continua a prosperar, sem ser quase afetada pelas realidades das crianças de nossos tempos. (SENGE et al., 2007, p. 20).

Parece que um modelo educacional que em boa parte dos países europeus tem sido superado ha algumas décadas, devido a reflexões autocríticas nas ciências sociais e educacionais, por outro lado está se espalhando principalmente nos países economicamente em ascensão com o pretexto de progresso e democratização. Nos países mencionados, por exemplo, o Brasil, a pressão ou adoção de medidas, atitudes e exigências neoliberais nos processos educacionais leva à falta de senso crítico e formação complexa de educadores, e em consequência a uma ou duas gerações de estudantes que estão atrofiando seus potenciais e habilidades criativos, porque precisam se submeter às condições "produtivas" da cadeia de reprodução de conhecimentos mecanizados, simplificados e desconexos, representando um retrocesso para todos que defendem o processo educacional como um processo humano, dialógico, aberto e criativo.

A maioria das pessoas nasce dentro de um sistema sociocultural relativamente definido e determinado, no qual aprendem a se submeter desde criança mediante processos educacionais disciplinantes e muitas vezes repressivos, sem poder dar atenção a seus desejos subjetivos, à sua própria voz! Jacoby (2000, p. 31) comenta que: "As expressões sonoras espontâneas da nossa vida social formam a base para todas expressões vocais artísticas. E de suma importância de se conscientizar desse processo e encontrar nessa base suas possibilidades pessoais”. Embora pareça ser uma constatação simples, percebe-se que muitas pessoas têm uma dificuldade enorme de encontrar a própria voz (na vida, como na música), em consonância com suas necessidades psicoemocionais e físicas e com as exigências do seu ambiente sociocultural. A causa não é necessariamente a ausência ou carência de valores, teorias e propósitos, mas muito mais um sinal do atrofiamento coletivo do ser orgânico, ou seja, da conexão vital entre consciência corporal, percepções sensoriais e seus processamentos cognitivos e 
psicoemocionais, assim como o feedback para o organismo. O autor ressalta a relação entre percepção corporal e desenvolvimento vocal, que não é somente técnica, mas também psicofísica, como resultado da interação contínua entre indivíduo e meio, levando a uma expressão única e individual. Os processos sensoriais e expressivos devem ser estudados a partir do desenvolvimento do bebê e da criança pequena, principalmente antes de ser "iniciado" ou até mesmo "corrompido" pelo mundo das regras escolares ou pré-escolares. As crianças desenvolvem nos primeiros anos da sua vida seu mundo interior, seus imaginários visuais, aurais, sensoriais etc. mediante muitos impulsos sensórios e sócio-afetivos. Principalmente na idade fantasmagórica entre 4 e 6 anos, ou até mais amplo, entre 2 e 9 anos, o cérebro triúnico (reptiliano, límbico e neo-cortex) da criança está em maior equilíbrio entre os três níveis e partes cerebrais: 1. Plano do organismo - realidade terrena e material da existência; 2. Plano do sócio-afetivo - realidade social da existencial; 3. Plano da consciência - realidade cognitiva e intelectual da existência. Nessa idade, os fundamentos são colocados para os processos de comunicação interna e externa que podem ser muito bem desenvolvidos ou limitados ou inibidos, de acordo com as disposições genéticas e físicas, assim como pelas influências educacionais, familiares, socioculturais e muitos outros fatores externos.

Tem duas direções polares em movimento em nós, uma força descendente e uma ascendente: integração e motivação, direção e motor, autonomia e autopoiese, consciência e metabolismo, espírito/mente e corpo, são dois polos complementares, dentre os quais nossa vida se move. O plano sócio-emocional cumpre a mediação e movimentação comunicativa e recursiva entre os outros planos. Nós reconhecemos os conceitos tradicionais corpo, mente, alma, numa dimensão nova e diferenciada, como os três planos do nosso cérebro triunico. (Ibid., p. 72).

O plano sócio-emocional, por sua vez, é acoplado ao sistema nervoso, o qual assume uma função-chave entre processos físicos funcionais e processos desencadeados pelos sentimentos e pensamentos. A parte mais importante é o amor e seus efeitos sobre o sistema nervoso, contribuindo imensamente para a vitalidade e presença do organismo como um todo e coloca em ação o processo interno do aprendizado essencial e orgânico. O amor e a aceitação sócio-afetiva promovem o fluxo e o movimento, que são necessários para o desenvolvimento, pois: "[...] se o movimento é inibido em alguns dos seus parâmetros (p. ex. por tabu, proibição, coerção), os polos se tornam independente e destrutivo" (ibid., p. 75). As consequências são conhecidas nas sociedades modernas e contemporâneas, marcadas pela separação habitual dos três planos, o que resulta numa insensibilidade generalizada e coolness ensaiada, 
reforçando comportamentos, que alienam os seres humanos dos seus sentimentos e percepções psicofísicos. Vários hábitos e comportamentos (auto)agressivos em forma de doenças (cancro, Alzheimer), excessos em beber, comer, relações sexuais, e vícios diversos (drogas, trabalho, computador, compras, ambição pelo poder), são os indícios de que o movimento complementar entre os polos está caindo aos pedaços, revelando uma estrutura social sob uma tensão violenta permanente. Jacoby (200) conclui que o estímulo e desenvolvimento da consciência sensorial, isto é, a comunicação interna de todos os planos de percepção física, emocional e cognitiva, poderia cumprir uma solução e função transformadora.

\section{MOVER-PERCEPÇÃOEEDUCAÇÃOESTÉTICA}

O professor de estética, artes e educação Wolfgang Krieger pesquisou e detalhou a relação dos processos de percepção e sua compreensão e importância para a educação estética na sua obra abrangente "Percepção e Educação estética”. Ele entrelaçou vários campos de pesquisa científica de forma interdisciplinar, construindo novos fundamentos e conceitos para a educação estética, tendo em conta o construtivismo radical e o paradigma da auto-organização, (autopoiese). Krieger aponta as dificuldades que se encontram quando se quer trazer a discussão estética de volta para a nossa experiência cotidiana, onde ela deveria estar.

A ignorância geral nas ciências sociais sobre as artes estéticas, é somente por parte uma consequência da autossuficiência racionalista. Ela não é menos fruto da auto-isolação elitista da teoria de artes, criada pelo conceito de uma estética distante do cotidiano, o qual, destituído da vivência sensorial, se tornou um modo de experiência intelectual, que depende da versatilidade do especialista em história da arte, para justificar sua existência. (KRIEGER, 2004, p. 13).

Nisso encontra-se o dilema das artes e da arte-educação: por um lado, "a quinta roda do carro", em pesquisa, prática e ensino, porque as ciências exatas são tratadas com prioridade (cargos, recursos, programas, materiais). Por outro lado, a famigerada autoisolação das artes, que se veste com o ar de arrogância para destacar que uma pessoa "comum", que não tenha desenvolvido habilidades sensíveis e conhecimentos específicos, mal poderia se aproximar desse "círculo seleto". Ambas as posições alienam o ser humano da vivência sensível e estética do cotidiano, que deveria acompanhar e alimentar a experiência criativa da vida.

Na Hermenêutica antigamente: A ciência do indivíduo pode concluir uma verdade gerando 
uma teoria meramente a partir da experiência real, numa teoria das percepções. No construtivismo ultimamente: a verdade geral do indivíduo são as condições possíveis de percepção. [...] Essa representação nos leva à questão do significado (no sentido das teorias de conhecimento) dos nossos órgãos perceptivos e da relatividade do nosso conceito de realidade. Quem determina de fato essa relatividade é a percepção, pois é ela que representa qualquer relação, qualquer ligação entre sujeito e mundo exterior, até mesmo a conexão do sujeito consigo mesmo. [...] Ela sempre será uma competência criativa e não apenas um espelho da realidade num sujeito passivo-reflexivo. (Ibid., p. 14-15).

Muito embora essa constatação seja óbvia, de que a percepção estética acontece mediante os órgãos perceptivos, que por sua vez influenciam e moldam nossos pensamentos, sentimentos e visão do mundo, nas teorias e práticas de educação é pouco levada em conta. A ciência se distanciou da base elementar e criativa, e os processos determinados pelos sentidos, nos quais se fundamentam a percepção, visão e construção do mundo, não são mais reconhecidos como essenciais. A abstração, objetivação e catalogação dos conhecimentos tomaram a frente ao decorrer dos séculos e esmagou o sujeito sensível com essa carga, sobretudo no modelo educacional neoliberal. O sujeito, por sua vez, acomodou-se na atitude consumista e se serve de acordo com a necessidade imediata nas prateleiras, em que conhecimentos são convocados em pequenas porções, fáceis de digerir, pressionando um botão, ou melhor, "clicando".

O desempenho próprio, que representa o passo decisivo no processo de aprendizagem, é conectado à percepção, ou seja, ao modus operandi da experiência estética. Trata-se da experiência criativa, a qual, segundo Krieger (2004), começa com o pensamento pré-concebido, no sentido das experiências elementares e sensoriais do bebê e da criança pequena, que formam a base para o desenvolvimento dos processos perceptivos e o aprendizado criativo. Quanto menor é a criança, quanto mais ela depende da atenção, do cuidado e do foco da mãe, do pai e de forma crescente de outras pessoas. Mesmo assim, ou justo por causa dessa dependência, ela é aberta e sensível, ao mesmo tempo para as suas sensações e percepções, e reage espontaneamente aos impulsos e incentivos externos, os busca e solicita, se relacionando com tudo que ouve, vê, sente, cheira, saboreia, toca. A complexidade da construção e do diálogo subjetivos com a realidade material e sociocultural da pequena criança mediante seus órgãos, sentidos, reações e interações levam à conclusão de que a escola formal muitas vezes tende a deformar mais do que formar uma pessoa. Na pedagogia construtivista, no entanto, a percepção estética forma a base do aprendizado e da apropriação 
e representação da realidade, como um princípio pedagógico criativo, e não para atender às exigências intelectuais e modas burguesas que exigem o aprendizado dos cânones artísticos dos séculos passados.

Se o pensar apreensivo ocorre pela percepção de todos os sentidos, que por sua vez estão interligados com as necessidades e vivências fisiológicos e psicoemocionais, esse processo pode ser considerado um processo estético, no qual forma e conteúdo são conectados inextricavelmente: "O conceito da educação estética nos serve aqui como denominação de um princípio pedagógico, que busca levar em conta esta nova relação" (Ibid., p. 24). Não se trata de aprender "arte", e sim do fato de que o processo inteiro de crescer e aprender pode ser considerado um processo criativo, que toma o sentimento estético como base. Isto não significa que o fato artístico e musical não teria mais um significado próprio, mas é importante compreender a ponderação específica do aprendizado estético no desenvolvimento integral das crianças, principalmente para incentivar e aproveitar esse potencial (latente e adormecido) de forma mais significativa:

A educação estética tem um papel-chave atualmente na crise do aprendizado escolar. A insuficiência da educação escolar, que se limita ao desempenho lógico-conceitual e a conhecimentos testáveis, devolve um novo significado para o aprendizado estético-lúdico como alternativa e perspectiva de modelos e formas novas de aprendizagem." (DAUER; SPRINKART, 1979, p. 7 apud KRIEGER, 2004, p. 97-98).

O autor põe a ênfase da educação estética na ideia de que ela deve ser vista como um modus operandi de aprendizado específico, assim reconquistando "[...] sua antiga função e importância como a doutrina da percepção sensorial" (Ibid., p. 98). Portanto, não se trata de conteúdos decorados, mas do como aprender, da construção e do acesso estéticos da realidade. Nas últimas décadas, quando se percebe uma mudança na educação, no sentido de compreender e reconhecer a importância do aprendizado como um processo biográfico ao longo da vida, a apropriação estética e subjetiva da realidade tem um novo peso que pode e deve ser ampliado para várias situações pedagógicas. A educação infantil, de jovens, da vivência e do lazer, constroem situações pedagógicas que são muito mais familiarizadas com os conteúdos e as metodologias estéticas e artísticas, porque priorizam o potencial criador da apropriação estética da realidade, o que não significa que deve ser excluído da rotina da escola regular.

O modus operandi da "apropriação ativa da realidade", está em contraste com os métodos passivos-receptivos da transmissão de conhecimentos no ensino escolar, que são 
criticados como monótonos pelos defensores da "educação estética", porque não levam em conta a competência e o potencial da cognição sensorial e tampouco a motivação individual dos alunos. O aprendizado pela experiência e a conexão recursiva a motivação individual mediante a apropriação criativa da realidade devem se tornar ponto de partida na metodologia, assim como o aprendizado 'conceitual' e 'interpretativo' na mediação racional de conhecimentos. (Ibid., p. 99).

Certamente essa visão não é nenhuma novidade, porque no início do século XX vários educadores e artistas contribuíram com a "Pedagogia da Reforma" na Europa, que ampliou a perspectiva pedagógica no sentido da apreensão estética da realidade que transformou a educação autoritária e materialista, dando ênfase à força criativa e subjetiva da criança. Justamente em relação a movimento, ritmo, música, dança e suas combinações e interações culturais surgiram fundamentos importantes, que não são contestados até hoje e devem ser discutidos e desenvolvidos nas variações estéticas e socioculturais. Proponho uma discussão crítica acerca das ideias e dos fundamentos filosóficos da Pedagogia da Reforma (SKIERA, 2003), da antroposofia e dos educadores musicais da primeira geração, porém aqui interessa principalmente a evolução que ela causou na educação estética, musical e sensorial que transformou substancialmente a educação infantil na Europa, quando suas ideias foram retomados nos anos 1960/70. Um dos pontos críticos da Pedagogia da Reforma, da antroposofia e do movimento da arte-educação a partir dos anos 1970 foi justamente a polarização exagerada entre o "racional" e o "emocional", a qual não faz justiça para nenhum dos aspectos.

O movimento da arte-educação aguçou a contradição entre o racional e o emocional para instrumentalizar as artes como uma força antagônica frente as ciências exatas e frente as tendências de controle e massificação do mundo tecnológico. O zelo quase religioso-confessional para o irracional, no entanto, impediu justamente um debate critico sobre o conceito de racionalidade do modernismo e reforçou a visão vigente da incompatibilidade entre razão e sentimento. O mesmo movimento de arte-educação, para o resto, ainda contribui para que as artes como sistema cultural pudesse ser ainda mais extraído e isolado da aliança dos sistemas culturais como um todo. Com esta atitude, o "mundo racional" manteve-se incontestado de possíveis e inovadores esforços do pensamento criativo. (Ibid., p. 105).

Superar a suposta incompatibilidade entre razão e sentimento nas mentes e nos corações dos seres humanos 
não é fácil: sobretudo na educação, encontra-se o dilema de que a maioria dos agentes dos processos educativos e formativos (professores, educadores, alunos, pais, gestores) pensam com a "tesoura na cabeça", no seu inconsciente corroborando essa "incompatibilidade", porque não conseguem ou não querem imaginar um conceito de aprendizado, no qual ela seria superada, em que razão e emoção pudessem trabalhar juntas. Krieger, no entanto, ressalta que, por outro lado, o grito para mais emotividade, corporeidade, criatividade e formas livres de expressão, como uma antípoda, somente reforçaria a dominância da racionalidade. Para sair desse dilema do pensamento antagônico, começa a soprar um vento novo, justamente vindo das ciências exatas e "racionais", pela física quântica e a neurobiologia, para encontrar um caminho no meio que possa levar mais criatividade, flexibilidade e potenciais para novas soluções, envolvendo ambos os lados da moeda. Mediante o viés das ciências naturais, que durante séculos se afastaram da natureza e da vitalidade dos acontecimentos, chegaram novos impulsos nas ciências sociais, que pareciam estar engessadas nos seus conceitos e autores consagrados, edificando construções sociais, educacionais e psicológicas que cada vez menos se mostram abertas e flexíveis para novas ações e atitudes humanas, subjetivas e culturalmente diversas.

A teoria da autopoiese, da auto-organização dos sistemas biológicos, levantou muita poeira em estudos interdisciplinares, o que os chilenos Maturana e Varela (1996) inicialmente não tinham previsto. Eles desenvolveram, a partir dos anos 1960, um conceito novo para o espírito-cognição: não se trata de uma coisa ou objeto, e sim de um processo - o verdadeiro princípio da vida que lembra a noção da relação "onda-partícula" na física quântica. Eles conseguiram unir duas tradições de pensamento sistêmico, quando reconheceram que o elo consiste na compreensão da "organização da vida": 1. A biologia dos organismos que investiga a essência das formas biológicas; e 2. A cibernética, que busca compreender a essência do espírito e da cognição. Criaram os fundamentos de uma teoria sistêmica da cognição, a qual equipara o processo de cognição com o processo vital. Sua definição da autopoiese mostra claramente a necessidade e condição de que todo ser humano tem a capacidade (e o direito) de aprender e se desenvolver, enunciado esse que deixa deduzir a importância de cada indivíduo para o sistema como um todo. As características da autopoiese são conhecidas como auto-organização, acoplamento estrutural e a capacidade de reprodução, inerentes a qualquer sujeito. Toda pessoa pode aprender a entrar em contato e se relacionar com o seu meio (sociocultural e natural), ativa e passivamente. O acoplamento estrutural é a absorção de contatos ativos e passivos, além das possibilidades de percepção e experiência, enquanto a capacidade de reprodução trata da possibilidade de mediar e absorver os pensamentos que surgem nos processos da percepção e experiência. Consequentemente, qualquer pessoa a 
qualquer momento é capaz de aprender, e torna-se decisivo com qual percepção o sistema autopoietico se envolve, ou escolhe se deixar envolver e processar. O conceito-chave nisso é a afirmação de que um sistema autopoiético decide com autonomia, sem ser imposto externamente, quais processos podem e devem ser realizados no seu sistema interno, o que levou na pedagogia para a mudança do paradigma em direção do construtivismo. Observando e conectando os sistemas biológicos, chega-se à conclusão de que as "categorias ideais", elaboradas (desejadas!) pelo ser humano, não correspondem aos processos e movimentos biológicos, como o ideal da estabilidade permanente.

Estabilidade como um estado homeostático de sistemas que se adaptaram uns aos outros, se revelou como uma miragem; a aparência macroscópica dos sistemas estáveis "em repouso" camufla o caos vital das microestruturas, das flutuações e oscilações dos elementos, que se escondem por trás dela. Assim pode se perder, o que permite aos sistemas auto-organizacionais de poder compensar mudanças criticas no seu meio, ou seja: o potencial de sistemas alternativos, que é capaz de surgir a partir das flutuações não ordenadas. Essa concepção não sacrificou o pensamento determinista para o principio do caos, mas integrou o principio do acaso no pensamento determinista. (Ibid., p. 141-142).

Podemos compreender melhor a estabilidade como um estado temporário do ser que surge por um momento no sistema vital, no qual ele se admira de estar no topo, mas logo cansa e se joga novamente no movimento geral, com uma intensidade lúdica e prazerosa para encontrar combinações melhores ou mais interessantes, o que o torna mais flexível e leva a mais comunicação e maior complexidade em geral. Esse movimento lembra o brincar da criança pequena, que imerge profundamente no jogo e na brincadeira e que procura e encontra (sem a intervenção objetiva de adultos), com elementos, objetos, materiais e o próprio corpo, novas combinações, formas e soluções, as quais na visão utilitária aparentemente não "fazem sentido", mas que liberam processos importantes na criança, a qual, mediante o brincar, embarca na busca dos sentidos da vida e de si mesma. A criança percebe intuitivamente o desafio do seu meio, de transformá-lo em uma brincadeira mágica, mediante objetos, pessoas, vivências e materiais ao seu alcance, assim contribuindo para que todos se relacionem de uma forma nova e inusitada e assumam novos significados. Quando as coisas e as pessoas são muito perfeitas, uniformes e ordenados, a criança se sente entediado e fica instigada a trazer um pouco de "desordem" nos acontecimentos e nos objetos da prateleira, porque intui que esse movimento seja o verdadeiro desafio e motor vital, corroborando a ideia de que 
Estabilidade no sentido de um equilíbrio absoluto não existe em sistemas auto-organizacionais. [...] e onde ela é atingida perto da perfeição, representa muito mais um perigo para o sistema, porque sua organização se revela nesse estado como extremamente vulnerável para as mudanças do meio-ambiente. Estabilidade neste sentido é de forma alguma um "estado ideal" para sistemas ecológicos, mas sim um estado de engessamento e de inflexibilidade. Para o estado da "resiliência", no entanto, é fundamental de que as instabilidades do sistema são utilizadas para gerar novas organizações que possam se empenhar melhor em utilizar os recursos do seu meio. (Ibid., p. 144).

Isso deixa refletir sobre o caos criativo de crianças que sentem a necessidade de descobrir e significar seu mundo subjetivo, sem ele ser imposto pelos adultos como um sistema acabado e estruturado: perfeito, sem graça e sem vida! O "estado ideal" da estabilidade e ordem seria então uma via única, no sentido da evolução, praticamente um suicídio! Crianças sentem isso, assim como os "loucos", os médiuns e alguns artistas e cientistas que ainda não foram corrompidos pelas organizações multinacionais. $\mathrm{O}$ mundo precisa ser recriado diariamente por cada indivíduo que se transforma e reinventa no seu meio num diálogo contínuo. A busca pela ordem e estabilidade, no final das contas, serve como força motriz, que motiva o ser humano a se mover, se relacionar, aprender e se recriar diariamente no sentido da evolução, o qual encontra no aprendizado um princípio fundador dos organismos vivos.

Como um sistema auto-organizacional, o cérebro recorre continuamente às estruturas que ele mesmo acaba de desenvolver. Esse procedimento presume sua capacidade de relacionar as características dos seus elementos, com outras palavras, presume auto-referencialidade. [...] no nível psicológico e fenomenal, isto é, a organização das funções psíquicas observado da "perspectiva macro" até mesmo nas pequenas mudanças celulares na "visão micro" de cada neurônio. (Ibid., p. 153).

A autorreferencialidade é o trunfo da criança, que ainda não foi esmagada pela "objetivação de estados e eventos alheios e abstratos da pedagogia corrente", a qual anula o valor da autorreferencialidade e quer convencer a criança de que ela não sabe nada e precisa ser orientada pelo que os outros sabem. No entanto, as neurociências mostram que no cérebro acontece uma troca permanente entre memória e conexões associativas, um processo que gera seus próprios instrumentos de avaliação e assim mantém um processo de aprendizagem circular, entre absorção de informação, consciência e criação de hipóteses, no qual participam fatores subjetivos, fisiológicos, 
psicoemocionais, entre outros. As atividades do cérebro, por sua vez, são alimentadas por vários níveis de percepção, e seu processamento acontece com a participação de sensações, percepções, emoções, palavras, sons, gestos e posturas corporais, principalmente na primeira infância, quando a linguagem verbal ainda não assumiu o domínio comunicativo. As competências de percepção sensorial são complexas e não representam funções robóticas que podem ser acedidas e desligadas por um clique.

A percepção humana é mais (e possivelmente algo muito diferente) do que somente a soma dos impulsos sensoriais individuais; ela é um esforço autônomo e criativo do cérebro, numa medida muito maior do que os modelos mecanicistas da biologia humana do século passado queriam admitir. (Ibid., p. 155).

Essas atividades que ocorrem de forma acoplada no cérebro e sistema nervoso são de grande complexidade e requerem estudos específicos da neurobiologia, porém,é importante lembrar que as percepções e sensações integram a participação do sistema nervoso, das atividades cerebrais, das emoções e de todo sistema hormonal, entre outros. $\mathrm{O}$ fator decisivo é que se trata de um processo subjetivo, no qual o "Eu" toma decisões, o que pode ser chamado de acoplamento recursivo, as quais preparam para o próximo passo: das experiências surgem hipóteses, e estas levam para ações que, por sua vez, trazem novas experiências, das quais surgem novas hipóteses etc., seguindo o lema: "[...] não pode ser descoberto nada, que antes não tem sido inventada" (Ibid., p. 175). Trata-se da relação criativa entre sujeito e objeto, entre indivíduo e meio, que é seletivo e que se dá a partir de vários níveis de percepção. Na nova relação que surge, torna-se evidente que indivíduo e meio se percebem, observam, influenciam, transformam mutualmente e se comportam de forma complementar: o pensamento da concriatividade (ROMBACH, 1994), que consiste, entre outros, no pensamento de que, a partir da percepção, surge a relação e ação e, portanto, algo novo, um terceiro elemento.

Na verdade, uma oferta para a percepção não é nem algo objetivo, nem algo subjetivo: poderíamos dizer que é as duas coisas ao mesmo tempo. Ela supera a dicotomia entre o subjetivo e o objetivo e nos ajuda, a compreender a inadequação dessa divisão. Uma oferta é ao mesmo tempo um fato e um comportamento do meio. Tanto e algo físico, como também algo psíquico e ao mesmo tempo nenhum dos dois. Uma oferta aponta para as duas direções, para o meio e para o observador. (GIBSON, 1982, p. 139 apud KRIEGER, 2004, p. 181). 


\footnotetext{
4 Em alemão, o verbo fazer, significa machen, o que leva ao poder $=$ macht, que mostra na etimologia da palavra, de que o poder vem do fazer, da ação humana.
}

\section{CRIAR - CONCRIATIVIDADE}

A ontologia estrutural do ser humano e da natureza constituem o objeto de estudo e reflexão do filósofo Heinrich Rombach, que observa e descreve a natureza - os ciclos, ritmos e as regras que movem a "Criação". Não obstante, o ser humano faz parte dessa criação; parece que ele se comporta como se não fizesse parte e não tivesse sujeito a leis e forças ordenadoras, que movem a "Criação", mas como o centro e a moção principal, assumindo um postura egocêntrica desde do iluminismo e cartesianismo que impregnaram as ciências no ocidente. A existência humana do ser, como parte de Criação, se desequilibrou para o fazer como poder ${ }^{4}$, ou seja, expressa a semântica dupla da palavra do poder: por um lado, a possibilidade do fazer, que se tornou independente como noção do poder, e como poder político/econômico/religioso/científico. Esta atitude se reflete em sistemas educacionais unilaterais, que priorizam o aprendizado funcional e mecanicistas, mesmo em situações em que se trabalha supostamente o ato criativo.

De fato, é um grande progresso quando p. ex. na pedagogia escolar não somente os conceitos: aprendizado, memorização, empenho e atenção tem um papel fundamental, mas quando a criatividade do aluno tem importância e encontra um espaço considerável na sala de aula. Mas isso geralmente permanece um espaço pouco iluminado, quando se trata de um fenômeno de preenchimentos de intervalos e margens. Essa descompasso tem sua origem na compreensão da ontologia equivocada do conceito da criatividade, que levou a um endeusamento do "Fazer/ poder" (a partir do ego humano), sobretudo na cultura ocidental: Tudo pode ser feito, só precisa dominar os meios. Sendo que os meios podem ser criados - este processo em vários estágios, se chama "técnica" ou mais recentemente "tecnologia" - (conclui-se) que tudo pode ser realizado (dominado) [...] (ROMBACH, 1994, p. 13).

A noção do empoderamento pelo fazer e/ou saber fazer certamente é fundamental para os processos educativos, porém traz um desequilíbrio grande quando distanciado de leis e forças da natureza e da "Criação" que consideram o ser humano como elemento criativo e colaborativo, e não como elemento de dominação da natureza. Rombach (1994) fornece uma chave para a compreensão de culturas ocidentais: posso fazer/realizar, isso me dá acesso ao poder! Isso virou um paradigma que sujeita todas as ações humanas ao dogma direcional, funcional e interessado: o aprendizado, o trabalho, a tecnologia e até mesmo a criação artística tem de se submeter aos objetivos utilitários humanos e se tornar um fator agressivo em várias dimensões. A própria Criação foi subjugada ao domínio do 
fazer, e mesmo a imagem de Deus, que na mitologia cristã é representada como um homem (!) que faz, que realiza como um humano, só que mais divino.

O domínio da ontologia do Fazer/Poder se revela sobretudo no fato de que e aplicada ao ato primordial da criação, quando o deus criador gera o mundo. Deus também "fizera" o mundo e ele "fizera" os homens, por forma-lo de um material a partir de um modelo, ou seja, ele mesmo. [...] Tudo já estava posto, criador, plano, material, forma, espaço, sentido e finalidade. [...] Mas nisso a essência do ato criativo já se perdeu e foi entregue irremediavelmente num espaço vazio, porque neste círculo das condições e categorias materiais pré-definidas, nada daquilo será possível, o que de fato define o Ser e o Ato criativo. (Ibid., p. 15).

Nessa definição utilitária do fazer, ele não é verdadeiramente criativo, porque no fundo tudo está posto e determinado e somente será combinado e executado em variações. Segundo Rombach (1994), não se trata de criatividade verdadeira, porque lhe faltaria uma característica determinante: uma nova dimensão que desencadeia o criativo. A essência do criativo seria marcada pela compreensão de que "[...] sendo somente aquela criação que com seu surgimento ao mesmo tempo gera uma nova dimensão para essa e outras criações. A essência é a dimensão e não o objeto" (Ibid., p. 15). Essa nova dimensão, a descoberta mediante e acerca de objetos, materiais, movimentos, sons e palavras, portanto, significa o ato criador, que desencadeia, move ou toca algo que não existia dessa forma até então, representando na maioria das vezes a ruptura com o habitual, a mudança dos paradigmas vigentes.

Um exemplo da história da música pode exemplificar essa nova dimensão, e em todas as artes e épocas encontramos exemplos maravilhosos para as (r)evoluções estéticas: o surgimento do Jazz! O historiador Hobsbawm reconheceu esta nova dimensão em afirmar que o Jazz seria a maior invenção do século XX. Duas culturas musicais completamente diferentes entram em choque no final do século XIX nos Estados Unidos: a cultura branca, cristã e dominadora e a cultura negra-africana, espiritual e escravizada naquela época. Dois sistemas musicais começam a se mesclar involuntariamente, pois os escravizados não tinham permissão de exercer e preservar suas formas musicais e cênicas, muito menos de tocarem instrumentos percussivos e tambores. Os negros começam a tocar a música cristã e militar dos brancos, inclusive muito melhor, e tecer aos poucos as formas musicais africanas flexíveis na estrutura rígida da música ocidental: as partituras começam a desenvolver uma vida própria e serem interpretadas na concepção da polifonia e polirritmia africana. 
${ }^{5}$ Uma criação de Rombach, que significa a presença e identificação sensorial e espontânea no tempo e espaço.
O estalo da uma nova dimensão representa ao mesmo tempo o surgimento de um novo Self. Uma auto-realização não seria possível de outra forma, a não ser, quando acontece o estalo de uma outra dimensão [...] Nesse processo surge aquilo que na cultura oriental e conhecido como o "Eu superior" [...] (Ibid., p. 20).

O Blues, o Jazz e todos os estilos e gêneros musicais derivados dessa fonte que surgiram ao longo de décadas formam uma nova dimensão, que representa uma espécie de "Eu superior", porque com o estalo dessa dimensão nova toda a história da música tem sido reescrita. Não somente a música em si começou a mudar, mas, com isso, a dança, a cultura popular, a relação entre música e expressão corporal, cênica e poética desencadearam uma fusão lenta, conflituosa, porém persistente das fronteiras entre negro e branco, pobre e rico, erudito e popular, entre outros antagonismos, porque pessoas de todas as origens, raças, classes, gêneros, idades começaram a se identificar com a música negra ao longo do século XX: "Aqui nos falamos de "Idemität's (idemidade), [...] uma palavra que num sentido mais amplo cabe aos grandes criadores, quando dizem: eu e a música, somos um só, eu e a poesia, somos um só, eu e o pensamento somos um só” (Ibid., p. 21).

Aquilo que Rombach denomina de idemidade é conhecido e experimentado por pessoas criativas, artisticamente ativas e/ou receptivas, que se envolvem constantemente ou mesmo por momentos em vivências e experiências estéticas e artísticas. É mais fácil de compreender esse fenômeno quando nos mergulhamos na música e na dança, porque o ritmo nos convence facilmente a deixar para trás nossa identidade verbal, mas também podemos conceber esse processo com as artes visuais e a poesia, entre outros. Não se deve ter a impressão de que se trata de uma arte "superior" e sublime, porque Rombach queria tratar muito mais da experiência concreta e elementar, comparada com a da criança imersa na brincadeira, mencionada anteriormente. Mais um exemplo da cultura infantil pode ilustrar a intensidade da idemidade: quando crianças brincam com a lama (terra e água), em pouco tempo começam a se lambuzar e pintar a si mesmas e umas às outras - elas trabalham de forma criativa com elementos primordiais e sentem intuitivamente como podem lidar com os materiais e que elas mesmas fazem parte desse acontecimento. O trabalho concreto com elementos e materiais é o começo do processo criativo, tanto no caso da criança lúdica como no caso do artista autônomo e do artesão e mestre de ofício.

Antigamente todos os ofícios eram determinados por uma espécie de concriatividade. Não era importante de fazer algo novo, mas se tratava de comprovar com uma simples ferramenta sua unidade nata com o material e seu mundo de formas. [...] Essa ideia vem 
acompanhada da experiência elementar, de que a partir de um determinado ponto, chamado de "breakthrough", a idemidade se instala, e a pessoa (o artesão/artista) não "faz" a obra, ele "é" a obra. [...] Infelizmente esse ponto decisivo foi perdido na última era humana. Tudo se "aprende", tudo se "sabe", se "fornece" o desempenho adequado - porém permanece de fora e intocado na essência. (Ibid., p. 22).

A falta de envolvimento verdadeiro e a distância da pessoa integrada com seu sistema corpo-mente-alma faz com que não se possa mais experimentar o processo da idemidade e colher com satisfação e emoção o fruto do próprio empenho. Além disso, se perde a felicidade do Flow e da confiança em si e em Deus/Universo. Entre crianças e artistas, pode ser observada uma dimensão a mais, que se junta como terceiro elemento esquivo, mas que pertence aos processos criativos como fator flexível e imprevisível, como um curinga no jogo ou um momento surpresa que se acrescenta por vontade própria ou não.

A concriatividade de pessoa para objeto, é expressa na linguagem coloquial pelo termo adequado: "vai!". [...] Neste fenômeno se revela uma independência e auto-atividade do "isso" (Id) que se retira sempre, quando ele esta para ser subjugado pelo domínio do poder. O ser humano experiente evita portanto, nos momentos que realmente importam, de usar os mecanismos do controle e da dominação e confia na sorte do "isso" que "vai". [...] Os momentos mais felizes da existência são aqueles, que surgem a partir da ordem superior do "Id" por ele mesmo. Ele não pode ser "feito" ou "não-feito". (Ibid., p. 25).

A compreensão do "Id", que "vai" quando bem quer, é uma experiência primordial do Ser e da confirmação da sua existência no seu lugar, e para poder vivenciá-lo, precisa-se de confiança e entrega, portanto uma mistura de autoconfiança e fé em Deus/Universo, o que pode ser expresso pelo conceito "Urvertrauen" - confiança primordial e elementar no Ser. A maioria das pessoas perdeu essa confiança primordial, ainda mais na medida em que as leis do "Fazer" (humano) e a crença da dominação da natureza pela tecnologia estão no topo do "sistema religioso" dos nossos tempos. Rombach (1994) considera a natureza como o grande artista, a qual cria incessantemente, na continuidade e segurança dos feitos ontológicos, sem os quais outras criações não seriam possíveis. Nada se inventa, mas tudo se cria e recria a partir da ontologia dos seres e objetos, abrindo novas dimensões do Ser: a concriatividade é um princípio elementar e ativo da natureza vital, sendo o ser humano, com suas habilidades, capacidades e desejos de criação e transformação, também uma parte da 
natureza, assim como o mais "insignificante" objeto. "Quem p. ex. considera a 'pedra' como morta, somente percebe uma fracção da pedra. A pedra que se apresenta na totalidade da sua estrutura, não a nada menos do que a Terra. A Terra vive. Ela tem uma longe historia [...]" (Ibid., p. 62). O autor chega às mesmas conclusões que muitos físicos quânticos, teóricos da cognição, místicos e pessoas espiritualmente iniciadas nas mais diversas culturas religiosas: a Terra vive, e é um sistema integral e orgânico! Ele investiga a tensão e relação na gênese estrutural entre aquilo que é produzido e oferecido pela natureza e aquilo que o ser humano faz e cria a partir disso, e como o próprio ser humano se relaciona com as criações naturais. Como os autores apresentados, Rombach interpreta o conceito da autopoiese de Maturana e Varela de forma mais ampla:

$\mathrm{Na}$ concepção estrutural, o conceito da auto-organização e visto diferente, isto é, que até a totalidade está "sendo", está sujeito às regras do jogo, e se comporta como um processo parcial, podendo ser corrigida. Ela não é o sistema, que se encontra na base da auto-organização, mas ela será composta a partir dos processos, fatores e atores parciais, como aquele totalidade, que possibilita a criação de novos processos parciais entre eles. A totalidade será criada "inventada", a partir de cada organismo de forma nova e bem-sucedida, ou seja, na recursividade positiva. [...] O sistema tem que ser intuído e recriado pelos processos, atores e fatores parciais e assim recebe sua forma original [...] Produzir aqui significa inventar, ser criativo, mesmo que somente "concriativo" (Ibid., p. 68).

No final das contas, educação e formação se trata dessa tensão e relação entre empatia e recriação das estruturas pré-existentes, que na criança e no jovem podem e devem levar a novos caminhos, soluções e criações. "A tarefa da existência pode ser vista neste perfil estrutural da gênese. A partir dai, surge o etos, o espírito e a cognição singulares e até o sentido de vida singular" (Ibid., p. 77).

A conclusão de que uma obra de arte, mas do que todo e qualquer processo de trabalho complexo, é coroada pelo momento decisivo quando "as coisas" vão por si só e tomam suas formas e seus caminhos quase que independentes. Para esse processo criativo, precisa de materiais, da técnica, assim como do esforço e trabalho manual e intelectual do ser humano, e finalmente da vontade e da intenção! Justamente na mistura entre concentração, habilidades e competências adquiridas, intenção, esforço e esperança pode-se juntar o "vai" de forma voluntaria: "O 'por si' não 'vai' sozinho! Não se pode simplesmente deixar as coisas andarem e escorregarem de qualquer jeito. Requer o esforço, empenho e o risco!” (Ibid., p. 82). Muitas pessoas conhecem a sensação de que, de repente, são inspiradas por ideias e que crescem forças imensuráveis nelas, 
quando se envolvem profundamente num processo criativo, que sempre estará aberto e imprevisível. Somente pelo investimento alto em trabalho, consistência e persistência pode surgir a inspiração do "Eu superior" que se junta ao "agora vai"! Mas, pelo visto, a crença geral no trabalho, como controle da tecnologia e do "Fazer-Poder", fez desaparecer a fé e a confiança no terceiro elemento incontrolável que "vai" em detrimento da ilusão da perfeição e do controle total do ser humano.

\section{TRANSFORMAR}

Os conceitos-processos da concriatividade, da autopoiese e do aprendizado orgânico levam à transformação das estruturas e formas até então existentes na medida em que a intenção acrescenta uma nova dimensão, na recriação e recombinação dos elementos, pensamentos, materiais e das estruturas. Surge a imagem de uma espiral flexível e móvel, diferente do círculo, porque tem um direcionamento. $\mathrm{O}$ abrir e fechar, o expandir e encolher, o absorver e expelir, tudo isso tem um fundamento cíclico, que aponta para o círculo, mas que não satisfaz a necessidade da criação, porque ele está fechado em si, "andando em círculos", literalmente uma situação na qual se retorna no ponto de partida sem evoluir. O círculo fechado pode ser muito importante para determinados momentos e situações rituais e criativos para poder se religar e receber novos impulsos e energias a partir da unidade formal construída, por exemplo, pode ser vivenciado nas danças circulares e sagradas. No entanto, como movimento vital e aprendiz, o vaivém direcionado da espiral representa muito mais o crescimento aberto e flexível do organismo em relação com o seu meio, no qual o interior e exterior se alimentam e equilibram mutualmente.

A estrutura interna somente se molda mediante o confronto real e vital com a estrutura externa [...]. Não existe uma verdadeira interno e externo, mas uma zona de transição relacional, que será consumado, lá e cá, pela estrutura em processos identificatórios. Sendo que dessa maneira as estruturas estão conectadas com todas as outras, surge mesmo a realidade estrutural. (Ibid., p. 114).

A realidade estrutural, na qual tudo está em relação e conexão com tudo, está sempre em movimento; abre-se e fecha-se, forma o dentro e fora, como estados temporários, atrai-se e se repele, numa dança do infinito, no qual espaço e tempo são conceitos relativos. Chegamos no campo das física quântica, que se alinha com a neurobiologia, com as teorias sistêmicas, preparando o caminho para o construtivismo a partir da visão filosófica. 
${ }^{6}<$ http://www.ihuonline.unisinos.br/index. php?option=com_content\&view=article\&id $=3628 \&$ secao $=349>$.
As estruturas estão sempre em movimento, num movimento interno. Ele compreende dobramento e desdobramento. Entre eles surge uma espécie de ápice, que não seria mais do que um momento, e não um repouso. A curva genética que conecta o crescimento e o declínio e sempre dobrada, em tensão, em movimento ascendente ou descendente, porque não ha permanência. (Ibid., p. 138).

As imagens dos fractais de Mandelbrot ${ }^{6}$ podem ajudar a ilustrar a complexidade, instabilidade e relatividade de cada organismo, partícula e impulso: uma rede móvel e conectada em transformação e construção permanente, no fluxo contínuo da ação de cada sujeito, sua memória e experiência de vida:
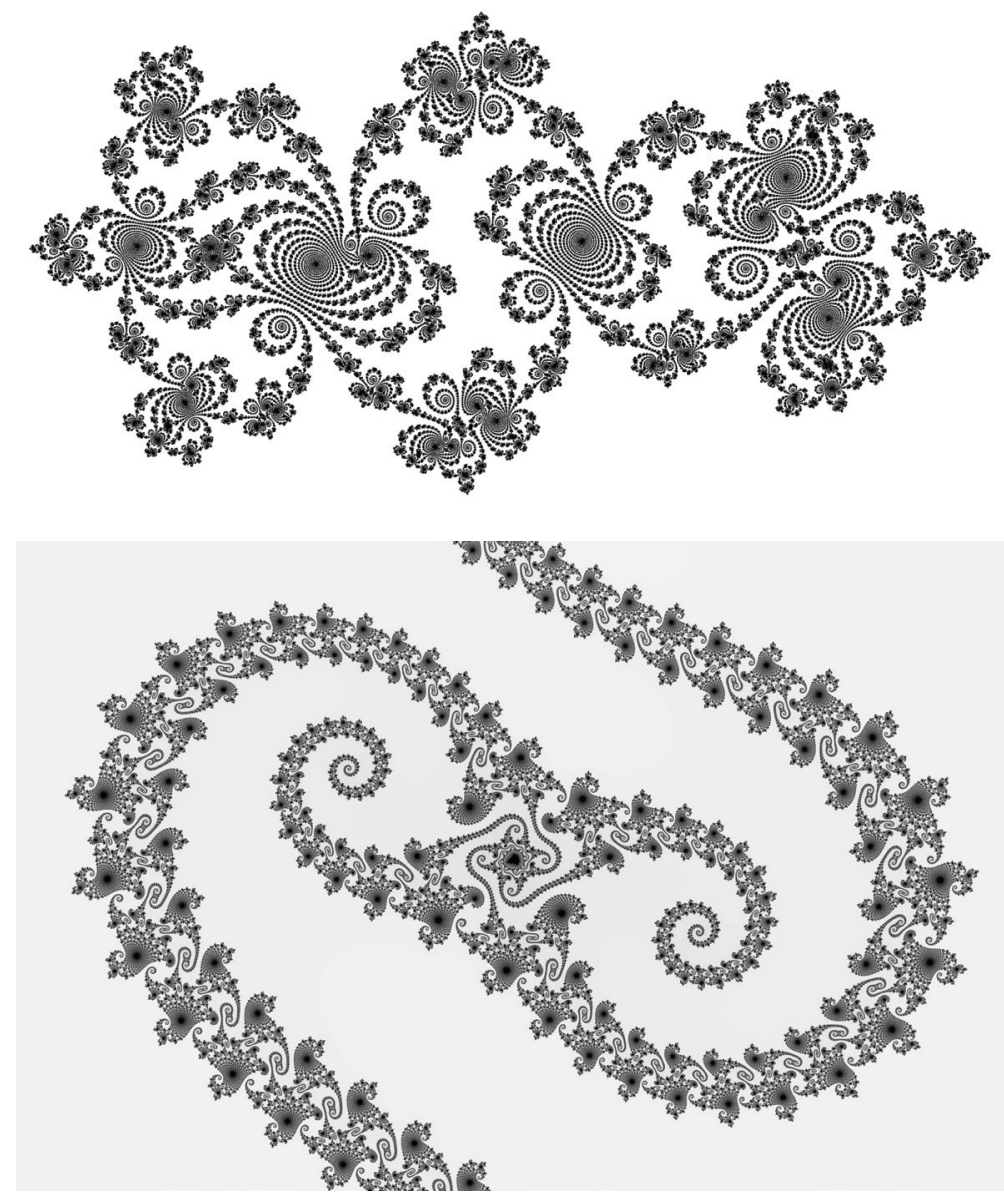

O questionamento que está por trás dessa discussão trata das dicotomias vigentes no nosso sistema sociocultural, educacional e político-econômico, ainda fortemente impregnado e determinado pelo pensamento dualista que definiu o mundo, ditando as categorias como positivo-negativo, branco-preto, rico-pobre, bem-mal, sem matizes, nuances, cores e subjetividades. Somos subjugados e compelidos desde pequenos em acreditar em linhas divisórias entre interno-externo, subjetivo-objetivo, psicofísico-racional, sim-não, certo-errado, feminino-masculino, entre muitos outros. Somos completamente subestimados 
e propositalmente atrofiados pelos meios de comunicação e educação para não confiar em nossos sentidos e percepções e deixar de desenvolver nossas conclusões, críticas e novas soluções, que possam levar a transformações individuais e coletivas mais profundas.

Krieger (2004) também entra no campo estético-filosófico como Rombach (1994), compreendendo as expressões e linguagens artísticas como uma das poucas áreas vitais, em que a vida multifacetada pode ser experimentada, contestada, recriada e transformada. A arte-educação teria, portanto, um papel fundamental para o desenvolvimento da percepção estética em primeiro lugar, que ajuda o sujeito a encontrar novos caminhos entre o caos e a ordem que se apresentam de muitas formas e aparências, a depender do tempo, espaço e contexto sociocultural. A própria arte dentro da visão e história ocidental corre o risco de ser mais um enquadramento sem vitalidade, se o ideal estético da beleza da tradição grega fosse a única referência sobre os valores da perfeição, simetria e harmonia. Parecido com o desdobramento de novas dimensões, teríamos de compreender que o desafio de uma vida criativa consiste muito mais nas rupturas com simetrias enfadonhas e ultrapassadas, isto é, na diversidade caótica de situações, condições, objetos e estados subjetivos que se encontram em movimento e mudança contínua. O dilema parece estar na visão dual que leva à exclusão do "outro", e não à integração e complementaridade dos diferentes e opostos. Na recepção e criação dos fenômenos estéticos são vivenciados todos os aspectos, mesmo os supostamente contraditórios da ação humana, e é reconhecido que existe a conexão complementar entre harmonia e dissonância, simetria e caos, forma e conteúdo, idealização e ruptura, entre outros. Essa conexão surge a partir das condições reais do meio que coloca à disposição "ofertas" irregulares e aleatórias, mas também a partir das oscilações internas das necessidades físicas, psicoemocionais e cognitivas.

A capacidade de identificar as instabilidades no campo da percepção pode ser compreendido na teoria da evolução como uma qualificação de sobrevivência. A necessidade da simetria se compreende neste sentido pela necessidade geral de identificar estruturas de percepção organizadas. [...] Visto por este ângulo, a criação de simetria representa também uma condição necessária para poder processar distinções. Sendo que elas quase nunca são encontradas de forma perfeita na natureza física, elas devem ser criadas de maneira fictícia pela construção ativa da experiência. (KRIEGER, 2004, p. 204).

O desafio individual consiste em encontrar um equilíbrio interno entre a necessidade de caos e simetria, porque ela seria muito mais uma construção idealizada que o ser humano necessita para vivenciar o subjetivo e 
distinguir a desordem e a diferença no seu campo de percepção: "simetria seria a situação normal, fisicamente improvável, porém funcional e utilitária, uma ficção normativa, na qual a diferença pode ser identificada" (Ibid., p. 204). Consequentemente, a percepção estética é um esforço criativo e diferenciado do indivíduo, que somente assim possibilita o desenvolvimento do todo. Toda diferença percebida e conscientizada gera uma marca, que fica na memória, sem importância se ela seja pequena ou grande. Um exemplo na literatura pode exemplificar isso, quando o sujeito poético começa a enxergar o mundo com outros olhos e quando "nada é mais como era antes", a partir de um corte brusco, uma mudança radical na trama. Em seguida, o/a protagonista é confrontado/a com um vendaval de acontecimentos caóticos, que exigem uma nova ordem.

Os processos de um estado organizado para um outro são chamados de transições caóticas. Essas transições são fases produtivas, nas quais novas organizações possam surgir, sobretudo em sistemas acopladas e recursivas. Elas são o próprio "momento criativo" do desenvolvimento do sistema. (Ibid., p. 205).

Mesmo sabendo da dificuldade de viver nas transições caóticas, tanto na vida individual como na evolução de povos e culturas, organizações e sistemas biológicos, entre outros, podemos observar que essas fases são marcadas pela intensidade de novas criações e dimensões, que deixam marcas intensas e douradoras na memória.

Rombach (1994, p. 142) nos faz lembrar a qualidade cíclica e efêmera desses acontecimentos e transições, que representam o dobrar e desdobrar, o expandir e encolher das estruturas: a ascensão e o declínio das culturas e na vida individual, vida e morte, pois "[...] todas as estruturas passam pelo ponto zero. Elas perecem e renascem”. Compreender essa circularidade representa uma força espiritual, que se perdeu na era tecnológica porque toda a energia se concentra no crescimento a todo custo: maior, melhor, mais-valia, perfeição e produção sem limites. No final das contas, atrás dessa corrida do mais e maior se esconde o medo da morte, o medo do declínio, da hora zero e do vazio, que, no entanto, se apresentam como uma pausa e um silêncio produtivo, comparado à ausência meditativa do Ego, que somente nesse vazio é capaz de se abrir para o verdadeiramente criativo, para a nova dimensão, no sentido da concriatividade: "Todo ser humano criativo sabe, que o surgimento de uma nova solução, um novo caminho somente pode ser o início $a b$ ovo, e que a plenitude da expansão corresponde ao vazio do encolhimento na mesma medida.” (Ibid., 142). A transformação de estruturas obsoletas somente pode acontecer na aceitação da morte do que não serve mais, superando o medo da "morte" do conhecido, da situação idealizada que perdeu os sinais vitais. Apesar da profundidade dessas reflexões filosóficas e intelectuais, no 
final, Rombach (1994, p. 162-163) deixa claro de que o elo dessa aceitação, superação e transformação sempre será o nosso corpo, a realidade física do nosso Ser, de cada Ser individual:

A criação é o corpo divino e a corporeidade não se opõe a divindade, [...] porque o corpo é humano e o palco das realizações vitais, que se envolve em concriatividade e idemidade na divergência multifacetada da unidade vital mediante o desafio e a afirmação reciproca. $A$ partir do corpo se dividem "corpo e espirito". No corpo são uma única coisa!

Voltamos para nosso ponto de partida com Jacoby, Krieger e muitos outros que reivindicam a necessidade de retornar ao corpo e, com isso, as sensações e percepções no centro da atenção novamente, ou seja, de nos devolver a humanidade nos processos educativos. Precisamos reaprender a dança da vida em movimentos livres, espontâneos, criativos que vivam o diálogo com o meio e possam expressar a qualidade individual de cada um, sem medo, sem finalidade imposta. Se olharmos para a grande diversidade das culturas populares brasileiras, temos um prato cheio para experimentar as mais diversas formas de se expressar com gesto, som, movimento, voz, palavra, traço, forma e cor.

Como um dançarino que experimenta e estuda movimentos, a criança se conhece na experimentação de novas formas e sons, que deixam rastros e marcos permanentes na sua percepção corporal. A criança vivencia a marcação dos rastros e a exploração do espaço no corpo em exercício e troca permanente com o ambiente e o outro, sem ela se dar conta desse esforço. O dançarino, no entanto, precisa "re-aprender" as formas livres, porque a "localização geométrica" do balé "adestrou" o seu corpo e o roubou da expressão da sua própria vontade, pressionando-o em padrões e posições absolutos:

Segundo von Laban somente a conexão entre a esfera dinâmica e a esfera cinética, gera a forma e em consequência o conteúdo - motion e emotion se tornarão com isso a preocupação principal da expressão gestaltica da dança. Os diversos pontos de vista com os quais ele analisa o movimento: perspectiva corporal, sensação dinâmica, e funções de controle - são parte de um todo do movimento. Sem dúvida, uma tal unidade existia nos tempos antigos, isto é, nos caminhos dos gestos que chamamos de traços e formas elementares. (SEITZ, 1996, p. 145).

Os "tempos antigos" remetem aos povos e às tradições que deixaram seus signos e traços antes da literalidade ao mundo posterior, e não somente nas cavernas e pedras, e sim nos corpos, inscritos nos sons, gestos e movimentos, 
os quais falam por eles mesmos. De fato, eles transmitem de geração em geração os saberes indizíveis mediante cantos, ritmos e danças "mágicas", cujos significados as crianças intuem sem palavras antes de serem pressionados nas formas estéticas e nos padrões linguísticos do seu tempo. É fascinante observar como crianças (e adultos) participam das expressões culturais brasileiras que colocam o corpo no centro das atenções: entram no flow, esquecem do meio, são lúdicos e concentrados ao mesmo tempo, se entregando ao ritmo e entrando em diálogo com a música e os participantes de uma forma integrada e sensorial, visível no rosto e gesto corporal. É de profunda importância estabelecer uma conexão entre as teorias contemporâneas de cognição, percepção e expressão e os saberes dos "tempos antigos", das nossas culturas ancestrais, preservados nos corpos e nas memórias de povos, grupos e expressões culturais, que atualmente estão sendo massacrados por políticas nacionais que novamente procuram excluir, combater, apagar, planificar, adestrar e padronizar a diversidade humana nas suas percepções e expressões estéticas, culturais e artísticas, sobretudo nos planos e contextos educativos e formativos.

\section{REFERÊNCIAS}

CSIKSZENTMIHALYI, Mihaly. Flow: The Psychology of Optimal Experience. New York: Harper and Row, 1990.

Creativity: Flow and the Psychology of Discovery and Invention. New York: Harper Perennial, 1996.

DÖRING, Katharina. Wahrnehmung und Ausdruck in afrobrasilianischen Tanz-Musik-Traditionen sinnlich-ästhetisches Lernen im Samba de Roda - Recôncavo. Dissertation, Univ. Siegen. Disponível em: <http:// dokumentix.ub.uni-siegen.de/opus/volltexte/2012/606>. Acesso em: 2 maio 2013.

JACOBY, Peter. Die eigene Stimme finden. Detmold: Blaue Eule Verlag, 2000.

KRIEGER, Wolfgang. Wahrnehmung und ästhetische Erziehung. Bochum: Projekt-Verlag, 2004.

MARIOTTI, Humberto. Autopoiese, cultura e sociedade. 1999. Disponível em: <http://www.geocities.com/ pluriversu/autopoies.html >. Acesso em: 2 maio 2013.

MATURANA, Humberto; VARELA, Francisco. A árvore do conhecimento. As bases psicológicas do entendimento humano. Campinas: Editorial Psy II, 1996.

MORIN, Edgar; LE MOIGNE, Jean Louis. A inteligência da complexidade. São Paulo: Peirópolis, 2000. 
162 PERCEBER, MOVER, CRIAR - PROCESSOS DE TRANSFORMAÇÃO

SEITZ, Hanne. Räume im Dazwischen. Bewegung, Spiel und Inszenierung im Kontext ästhetischer Theorie und Praxis. Essen: Klartext Verlag, 1996.

SENGE, Peter et al. Presença. Propósito humano e o campo do futuro. São Paulo: Cultrix, 2007.

SKIERA, Ehrenhard. Reformpädagogik in Geschichte und Gegenwart. München: Wissenschaftsverlag, 2003. 